УДК 330.3

\author{
В. А. Оглоблин \\ Иркутский государственный университет путей сообщения, \\ г. Иркутск, Российская Федерация \\ В. Г. Вихорев \\ Иркутский национальный исследовательский технический университет, \\ г. Иркутск, Российская Федерация \\ М. В. Вихорева \\ Байкальский государственный университет, \\ г. Иркутск, Российская Федерация
}

\title{
СПОСОБЫ ПОВЫШЕНИЯ СТЕПЕНИ ИННОВАЦИОННОСТИ ЭКОНОМИКИ
}

\begin{abstract}
АНнОтАЦия. Для повышения степени инновационности экономики необходимы изменения инновационной инфраструктуры. Однако ландшафт инновационной инфраструктуры зависит от того, какого вида инновации больше нужны экономике. Как правило, изменение ландшафта инновационной инфраструктуры происходит стихийно. По нашему мнению, этим процессом необходимо управлять. В статье приводится перечень видов инноваций, на которых необходимо сосредоточиться России в современных условиях, обосновывается их выбор. Предпосылки развития инновационной инфраструктуры авторы видят в степени развитости Интернета в стране, высоком уровне образования населения, доступности материалов и инструментов, используемых в опытно-конструкторских разработках, а также в современных возможностях производства материалов и инструментов по индивидуальным параметрам. Рассматриваются некоторые способы увеличения количества предлагаемых видов инноваций и приводится общий план развития инновационной инфраструктуры путем совершенствования кадрового менеджмента на предприятиях. кЛючЕВЫЕ словА. Инновация; инновационная инфраструктура; кадровый менеджмент.
\end{abstract}

ИНФОРМАЦИЯ О СТАТЬЕ. Дата поступления 16 февраля 2016 г.; дата принятия к печати 26 февраля 2016 г.; дата онлайн-размещения 31 марта 2016 г.

\author{
V. A. Ogloblin \\ Irkutsk State Railway Engineering University, \\ Irkutsk, Russian Federation \\ V. G. Vikhorev \\ Irkutsk National Research Technical University, \\ Irkutsk, Russian Federation \\ M. V. Vikhoreva \\ Baikal State University, \\ Irkutsk, Russian Federation
}

\section{WAYS OF INCREASING THE DEGREE OF ECONOMIC INNOVATIVENESS}

ABSTRACT. Increasing the degree of economic innovativeness requires necessary changes of innovation infrastructure. However, the landscape of innovation infrastructure depends on what types of innovation the economy needs. As a rule, changes of the innovation infrastructure landscape occur on the spur of the moment. In our opinion, this process must be controlled. The article presents a list of innovation types Russia has to concentrate on in the current context, as well as substantiates their selection. The authors see the prerequisites of developing the innovation infrastructure in degree of the Internet development, high level of public education, availability of materials and engineering tools used in experimental developments as well as in modern facilities for production materials and tools according to individual parameters. The article

\section{Baikal Research Journal}


considers certain ways of increasing the number of the proposed types of innovations and presents a general plan of developing the innovation infrastructure by improving personnel management at enterprises.

KEYWORDS. Innovation; innovation infrastructure; personnel management.

ARTICLE INFO. Received February 16, 2016; accepted February 26, 2016; available on-

line March 31, 2016.

Инновационная экономика позволяет добиться высокого уровня качества жизни населения. Нет сомнения, что инновационность экономики достигается при помощи соответствующей инновационной инфраструктуры. Однако к определениям понятия «инновационная инфраструктура» есть разные подходы [1]. Например, можно привести определение из официального документа «Регламент Осло» - это общая институциональная среда, создающая базовые условия, в которых создается инновация и относятся следующие элементы:

- система образования;

- инфраструктура транспорта и связи;

- финансовые институты, определяющие доступность венчурного капитала;

- законодательные и макроэкономические установки, такие как патентное право, налоги, корпоративная политика и система регулирования процентных ставок, тарифы и конкуренция;

- доступность рынка, включая возможность установления взаимоотношений с потребителем, включая размер рынка и его доступность;

- структура промышленности и конкурентная среда, включая поставщиков и комплементарные секторы промышленности.

Попробуем понять источник возникновения элементов инновационной инфраструктуры. Для этого рассмотрим этапы инновационного процесса [2], которые подробно описаны Р. И. Акмаевой [3] и состоят из следующих элементов:

1. Фундаментальные исследования - сбор и систематизация информации по соответствующей проблеме о потребностях и тенденциях развития.

2. Прикладные исследования - определение способов применения результатов предыдущего этапа и их уточнение.

3. Опытно-конструкторские работы - создание новых образцов, прошедших испытания и пригодных для производственного и коммерческого использования.

Освоение производства нового изделия, одновременно включает и потребление (рис. 1).

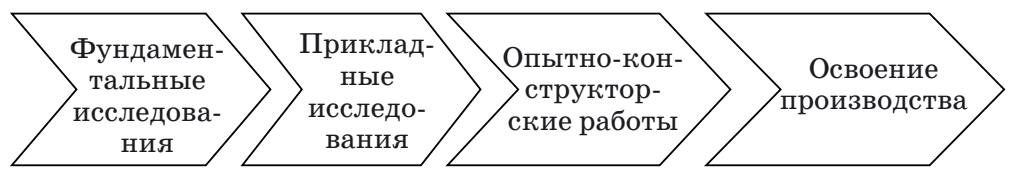

Рис. 1. Этапы инновационного процесса

Соответственно, для обеспечения деятельности данного процесса необходимы все перечисленные элементы инновационной инфраструктуры.

Анализ структуры научно-инновационного цикла показывает, что в цепочке «исследование - разработка» время разработки новой фундаментальной идеи или совершения открытия не уменьшилось и во многом зависит от неуправляемых факторов - таланта исследователя, случайного озарения, т. е. комплекса творческих компонентов. В то же время период получения результатов в прикладных исследованиях и разработках за последние десятилетия сократился в среднем с 10-12 до 3-4 лет, а по отдельным научным направлениям (био- и нанотехнологии, прикладная математика и ряд других) до 6-8 мес. В течение нынешнего десятилетия можно

\section{Baikal Research Journal}


ожидать сокращения сроков внедрения исследований и разработок еще как минимум в $1,5-2,0$ раза [4].

Таким образом, наиболее трудоемкий этап - это этап фундаментальных исследований. Более того, именно этот этап имеет наибольшие риски невозврата инвестиций, поэтому на данном этапе роль инвестора берет на себя государство, либо крупные корпоративные структуры и очень сложно привлечь средства частного инвестора. В России в 2012 г. крупными корпоративными структурами было профинансировано $35 \%$ затрат на научно-исследовательские и опытно-конструкторские работы, против $83 \%$ в США и 93 \% в Китае за тот же период [5]. Отечественные корпоративные структуры по разным причинам в этом не заинтересованы, возможности российского государства в связи с известными событиями также ограничены. Однако если рассматривать научно-инновационный цикл без первого этапа, то он становится крайне привлекательным для вложения денег в создание инноваций. Период возврата инвестиций и получения прибыли может составлять от 1,5 до 2 лет в зависимости от отрасли. Именно этот подход в свое время выбрала Япония - вместо ожидания результатов своих научных исследований японцы покупали их в других странах [6].

Инновации могут отличаться по различным параметрам, например, по масштабам влияния на экономику. Хотя надо отметить, что классификаций инноваций существует большое количество [7]. Так, Ю. В. Яковец предлагает классификацию с точки зрения циклического развития науки и техники [8]:

- крупнейшие базисные инновации - способствуют формированию новых направлений техники, требуют крупных затрат и длительного времени для освоения;

- крупные инновации - содействуют формированию новых поколений техники в рамках определенного направления, реализуются в более короткие сроки и с меньшими затратами, чем базисные инновации;

- средние инновации - реализуют изобретения того же уровня и служат базой для создания новых моделей и модификаций данного поколения техники, заменяющих устаревшие модели более эффективными, либо расширяющих сферу применения этого поколения;

- мелкие инновации - улучшают отдельные производственные или потребительские параметры выпускаемых моделей техники.

В сложившейся ситуации в экономике России предлагаем сосредоточиться на создании средних и мелких инноваций, с целью восстановить затем производство крупных и крупнейших инноваций.

Крупнейшими базисными инновациями занимаются научно-исследовательские организации (традиционно мощное направление было в Советском Союзе, но России досталось не в лучшем состоянии), а крупными инновациями - исследовательские отделы в крупных корпорациях (только зарождающееся направление в России). В ходе исследований на уровне крупных инноваций появляется масса средних и мелких инноваций, но дело в том, что исследователи намеренно проходят мимо многих и многих идей, которые в дальнейшем могли бы стать средними и мелкими инновациями. Причин тому много и одна из важных - основные исследования лежат в другой плоскости, нежели открывшиеся возможности, и просто не финансируются. Наконец, исследователям не хватает времени проработать все открывшиеся варианты, при этом конечно же отсутствуют результаты маркетинговых исследований предпочтений потребителей по полученным в результате исследований возможностям.

Считаем, что средние и мелкие инновации могут и должны привлечь внимание рынка, доказательства данной точки зрения приведены в предыдущей нашей статье [9].

$\Phi$. Котлер считает, что удовлетворение потребностей потребителей происходит от нужды к осознанию потребности и далее (рис. 2) [10]. Однако может быть так, что товара для соответствующей потребности еще не создано, тогда без инновации такую по-

\section{Baikal Research Journal}

электронный научный журнал Байкальского государственного университета 
требность удовлетворить невозможно, поэтому общим случаем схемы удовлетворения потребности потребителя будем считать следующий порядок, приведенный на рис. 3.

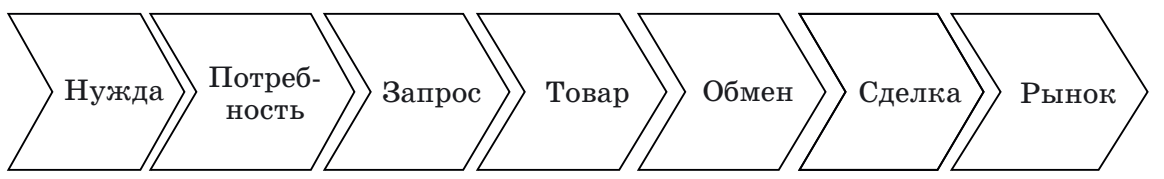

Рис. 2. Схема удовлетворения потребностей потребителей

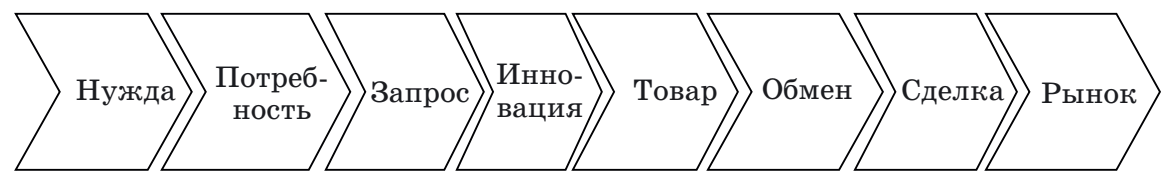

Рис. 3. Схема удовлетворения потребностей потребителей с учетом создания инноваций

Ф. Котлер также предложил схему удовлетворения потребностей потребителей исходя из маркетингового подхода, все остальные детали он опустил ради формирования самой сути маркетинга. Например, государство устанавливает конкретные правила работы рынка, финансовой системы и т. д. Учитывая, что процесс инновации включает в себя четыре этапа (причем первый из них мы опустим, так как его можно осуществить только с поддержкой государства, либо крупной корпоративной структуры), тогда этапы инновационного процесса можно представить как:

- сбор информации о результатах фундаментальных исследований по соответствующей проблеме рассматриваемой нужды;

- прикладные исследования применения результатов фундаментальных исследований по соответствующей проблеме рассматриваемой нужды;

- опытно-конструкторские разработки направлены на создание новых образцов, прошедших испытания и пригодных для производственного и коммерческого использования по соответствующей проблеме рассматриваемой нужды;

- освоение производства нового изделия.

Инновационная инфраструктура должна поддерживать перечисленные этапы инновационного процесса. В зависимости от задач, стоящих перед инновационной инфраструктурой, можно говорить о конфигурации или ландшафте инновационной инфраструктуры. Авторы предлагают следующее определение понятию «ландшафт инновационной инфраструктуры» - это определенное сочетание уровней развития элементов инновационной инфраструктуры, направленной на достижение целей по развитию инновационности экономики.

Итак, что может способствовать повышению числа инноваций (как продуктов, так и услуг)? По нашему мнению, тут может быть только два пути:

1. Новая технология на базе информационных технологий, которая сможет связывать нужду с результатами фундаментальных исследований.

2. Увеличение числа людей, разрабатывающих инновации.

Первый способ весьма перспективен в плане производительности, но его появление возможно только при наличии результатов фундаментальных исследований, вероятно в области искусственного интеллекта. Поскольку финансирование таких исследований по силам только государствам или крупным корпоративным структурам, то обсуждать данный способ в этой статье мы не будем.

Второй способ экстенсивен по своей сути, но относительно дешев и имеет несколько дополнительных преимуществ, например привлекает широкие слои насе-

\section{Baikal Research Journal}


ления к инновационному процессу. Как и отмечалось ранее, осознав нужду в новой услуге или товаре, но не найдя ее на рынке, инноваторы попытаются найти способ создания нового продукта. Информацию можно получить в Интернете, либо в специализированных учреждениях вроде патентного бюро. Дальше человек может попытаться материально воплотить товар или средство для оказания услуги. Для этого ему потребуются инструменты и материалы, как стандартные, так и сделанные под заказ по индивидуальным параметрам. После получения опытного образца необходимо запустить в массовое производство новый товар, а это уже обычный проект с разработкой бизнес-плана и поиском инвестора.

Рассмотрим факторы, способствующие вовлечению населения в инновационную деятельность:

1. Доступность информации об изобретениях с помощью Интернета. Всемирный экономический форум каждый год публикует отчет об индексе готовности к сетевому обществу (Networked Readiness Index - NRI). Это комплексный показатель, отражающий готовность экономики стран мира к использованию информационно-телекоммуникационных технологий для ускорения развития. Так, в 2013 г. Россия заняла 54-е место из 144, что на две позиции лучше прошлогоднего показателя и на 24 позиции выше 80-й позиции в 2010 г. При этом Россия обошла Китай, который занял 58-е место [11].

По мнению авторов, в России Интернет развит в такой степени, что доступен практически каждому члену общества.

2. Высокий уровень образования населения. Необходимо отметить, что человек, имеющий высшее образование, более способен к производству инноваций, чем человек, имеющий среднее образование. Возможны исключения из правил, но для общей картины это утверждение верно по очевидным причинам.

Так, динамика численности обучающихся за 2000-2011 гг. свидетельствует о том, что каждый год около 7 млн людей получают высшее образование (рис. 4). Сравнение удельного веса населения, имеющего высшее и послевузовское профессиональное образование к общей его численности по возрастным группам в 2010 г., показывает, что в России, Республике Кореи, Польше, Японии, США, Швеции, Финляндии и Норвегии более трети населения в возрасте от 25 до 34 лет имеют высшее образование (рис. 5). Таким образом, Россия имеет необходимый ресурс в виде уровня образования населения для повышения степени инновационности экономики.

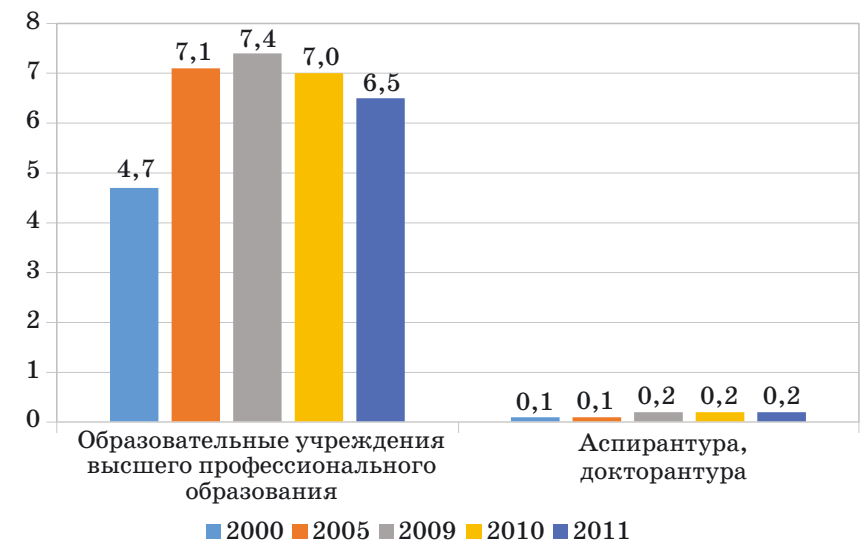

Рис. 4. Диналика численности обучающихся за 2000-2011 г2.

в образовательных учреждениях высшего профессионального образования, аспирантуре и докторантуре, ллн чел.

(Источник: Индикаторы образования: 2013: стат. сб. М. : НИУ ВШЭ, 2013.280 с.)

\section{Baikal Research Journal}




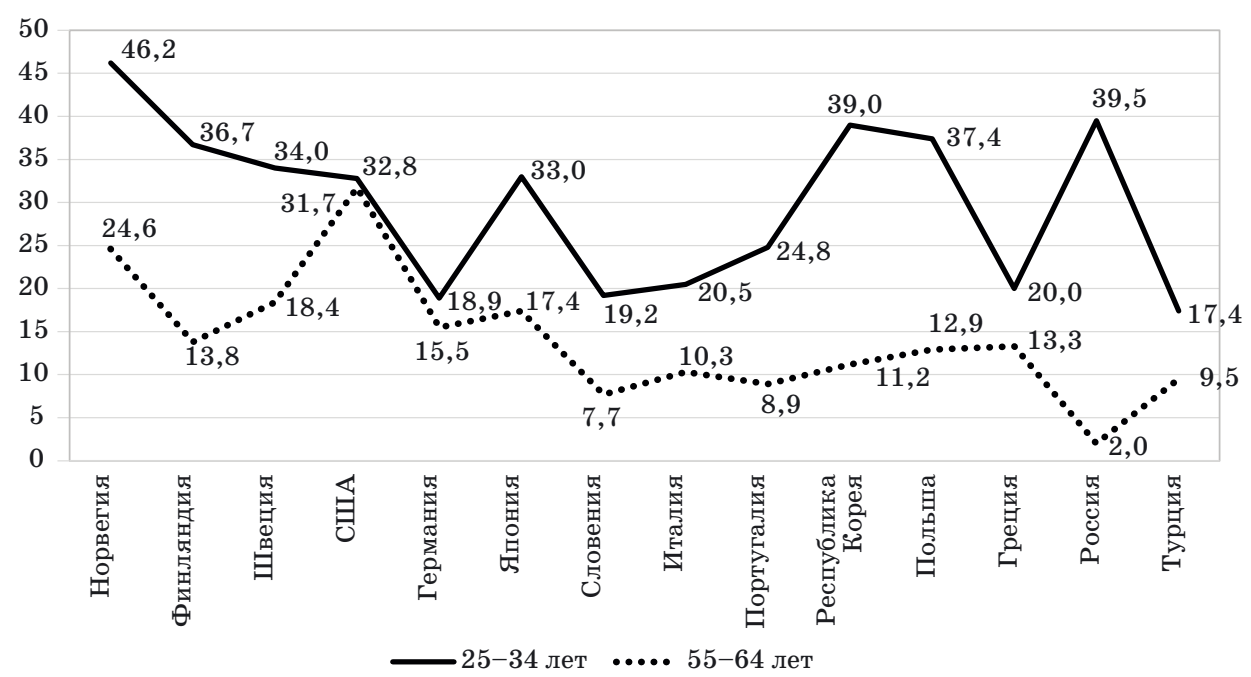

Рис. 5. Удельный вес населения, илеющего высшее и послевузовское профессиональное образование к общей его численности по возрастныл группам в 2010 г.

(Источник: Индикаторы образования: 2013 : стат. сб. М. : НИУ ВШЭ, 2013. 280 с.)

Конечно, возникает вопрос о качестве высшего образования. Например, по мнению британской компании «QS Quacquarelli Symonds», в рейтинге лучших вузов мира за 2013 г. Московский государственный университет находится пока на 120 -м месте ${ }^{1}$. Однако Правительство РФ ставит задачу вхождения в сотню лучших вузов мира пяти российских вузов к 2020 г., поэтому можно говорить о том, что качество обучения будет расти в стране.

3. Продолжающее снижение цен на материалы и инструменты, в том числе используемые в опытно-конструкторских разработках.

4. Производство материалов и инструментов, в том числе используемых в опытно-конструкторских разработках, по индивидуальным параметрам.

Таким образом, мы видим, что условия для массового производства инноваций России уже сложились: значительная часть населения имеет достаточный уровень образования, доступ к инфраструктуре для поддержки инновационной деятельности.

Отметим, чего не хватает для привлечения населения к инновационной деятельности. Можно привести массу примеров об идеях новых товаров или услуг (например, кольцо для открытия пивной банки и т. д.). Однако появившаяся идея требует доработки и неизвестно сколько инноваций никогда не увидели свет только потому, что автор, высказавший идею инноваций, не знал как ее «довести до ума» .

В работе над инновацией зачастую встречаются следующие трудности:

1. Отсутствие возможности получения консультации у эксперта в требуемой области знаний по оценке идеи, а также порядку проведения опытно-конструкторских работ. Поскольку узаконить права на инновацию (получить патент) многим представляется чрезвычайно трудоемким и почти невозможным, то начинающие инноваторы боятся даже рассказывать о своей идее, считая, что ее тут же присвоят. В данной статье не будем рассматривать вопрос о правовом регулировании инновационной деятельности, так как он слишком сложен.

2. Проведение опытно-конструкторских работ в специализированной лаборатории. По нашему мнению, специализированные лаборатории следует создавать на

${ }^{1}$ URL : http://ria.ru/sn_edu/20130910/956477049.html.

\section{Baikal Research Journal}


базе предприятий, а их деятельность должна быть направлена на развитие в той области, в которой осуществляет деятельность данное предприятие. Издержки на создание и эксплуатацию лаборатории невысоки, а вот выгода может быть очень велика. Например, это произведенные инновации и, что более ценно, найденные специалисты, которых можно привлечь к работе в данной компании. Работу по созданию лаборатории можно поручить отделу управления человеческими ресурсами совместно с технической службой, так как в рамках обычной работы с персоналом данную деятельность будет осуществить достаточно сложно. В связи с этим необходимо расширить содержание кадрового менеджмента на предприятии и включить недостающие этапы: от привлечения инноваторов до процедуры завершения сотрудничества. Понадобятся социальные технологии для поиска неординарных людей, продвижение бренда работодателя, технология «управление талантами» и т. д. Однако и организацию работы с инноваторами следует поменять - она должна стать проектно ориентированной, где на выходе требуется конкретный результат в виде инновационного продукта. Инноватор, создавший продукт, который может быть использован в производстве компании, должен быть привлечен к работе в этом предприятии на взаимовыгодных условиях. При этом в регионе может не оказаться предприятия, которое может заинтересоваться некоторой идеей гражданина, в таком случае необходимо создать так называемые «народные лаборатории» при научно-исследовательских институтах. Цель их функционирования - первичная консультация, экспертиза идей, юридическая помощь и, если необходимо, обучение.

Проблема привлечения населения в такую лабораторию может решаться как самим предприятием, так и органами местного самоуправления или государственного управления в рамках соответствующих программ, например в рамках программы государственной поддержки малого и среднего бизнеса. Некоторые административные единицы Сибирского Федерального округа СФО (например, Новосибирская область) уже сейчас используют в качестве критериев оценки поддержки малого и среднего предпринимательства показатель, характеризующий инновационную деятельность малого и среднего предпринимательства [12].

Ожидаемыми результатами поддержки инновационных идей помимо увеличения количества разрабатываемых инноваций может стать то, что большое количество людей займется общественно полезной деятельностью и отвлечется от праздной, а иногда и криминальной деятельности. Такое занятие может выявить недостаток знаний и люди пойдут учиться в вузы в поисках решения своей проблемы. Предприятия, участвующие в такой программе, получат конкурентное преимущество, талантливых сотрудников, а также усовершенствуют свой кадровый менеджмент.

\section{Список использованной литературы}

1. Семке Ю. С. Сущность и основные элементы инновационная инфраструктуры / Ю. С. Семке // Вестник-Экономист (Забайкальский государственный университет). 2012. - № 4. - C. 1-8.

2. Нурпеисов Б. Г. Сущность, признаки и этапы инновационного процесса / Б. Г. Нурпеисов / Вестник Карагандинского государственного университета. Сер. Экономика. - 2013. № 1 (69). - C. 46-52.

3. Акмаева Р. И. Инновационный менеджмент : учеб. пособие / Р. И. Акмаева. - Ростов н/Д : Феникс, 2009. -347 с.

4. Миндели Л. Э. Как сохранить Российскую фундаментальную науку? / Л. Э. Миндели, Л. К. Пипия // Вестник Российской академии наук. - 2002. - Т. 72, № 2. - С. 99-106.

5. Ульянов А. О. Проблемы и перспективы развития инновационной деятельности российских транснациональных корпораций [Электронный ресурс] / А. О. Ульянов // Известия Иркутской государственной экономической академии (Байкальский государственный университет экономики и права). - 2015. — Т. 6, № 1. — DOI : 10.17150/2072-0904.2015.6(1).18.

\section{Baikal Research Journal}

электронный научный журнал Байкальского государственного университета 
6. Омельченко А. А. Инновационное развитие российской экономики / А. А. Омельченко // Молодой ученый. - 2011. - Т. 1, № 12. - С. 167-170.

7. Козлова Ж⿱. М. Анализ подходов к классификации инноваций / Ж. М. Козлова // Вестник Алтайской академии экономики и права. - 2011. — № 4 (22). — С. 65-67.

8. Инновации: теория, механизмы, государственное регулирование : учеб. пособие / под ред. Ю. В. Яковца. - М. : Изд-во Рос. акад. нар. хоз-ва и гос. службы при Президенте РФ (РАНХиГС), 2002. - 237 с.

9. Оглоблин В. А. Некоторые аспекты сервисного подхода к понятию «инновация» [Электронный ресурс] / В. А. Оглоблин, В. Г. Вихорев, М. В. Вихорева // Известия Иркутской государственной экономической академии (Байкальский государственный университет экономики и права). - 2015. - Т. 6, № 3. - DOI : 10.17150/2072-0904.2015.6(3).22.

10. Котлер Ф. Маркетинг. Гостеприимство. Туризм : учебник / Ф. Котлер, Дж. Боуэн, Дж. Мейкенз. - 2-е изд., перераб. и доп. - М. : Юнити-Дана, 2002. — 1063 с.

11. Аксенов А. Международные рейтинги уровня развития ИКТ. 2014 [Электронный ресурс] / А. Аксенов. - Режим доступа : http:// d-russia.ru/mezhdunarodnye-rejtingi-urovnyarazvitiya-ikt.html.

12. Киреенко А. П. Применение программно-целевого метода для государственной поддержки малого и среднего предпринимательства в регионах Сибирского федерального округа / А. П. Киреенко, Л. В. Санина // Известия Иркутской государственной экономической академии. - 2014. - № 4 (96). - С. 117-132.

\section{References}

1. Semke Yu. S. Essence and basic elements of innovative infrastructure. Vestnik-Ekonomist (Zabaikal'skii gosudarstvennyi universitet) = Bulletin-Economist (Zabaikalsky State University ), 2012, no. 4, pp. 1-8. (In Russian).

2. Nurpeisov B. G. Essence, features and stages of innovative process. Vestnik Karagandinskogo gosudarstvennogo universiteta. Seriya: Ekonomika = Bulletin of Karaganda University, Series: Economics, 2013, no. 1 (69), pp. 46-52. (In Russian).

3. Akmayeva R. I. Innovatcion'yi manegment [Innovative management]. Rostov-on-Don, Feniks Publ., 2009. 347 p.

4. Mindeli L. A., Pipiya L. K. How to keep the Russian fundamental science? Vestnik Rossi iskoi akademii nayk = Bulletin of Russian Academy of Sciences, 2002, vol. 72, no. 2, pp. 99-106. (In Russian).

5. Ulyanov A. O. Problems and prospects of developing innovative activities of Russian transnational corporations. Izvestiya Irkutskoy gosudarstvennoy ekonomicheskoy akademii (Baykalskiy gosudarstvennyy universitet ekonomiki i prava) = Bulletin of Irkutsk State Economics Academy (Baikal State University of Economics and Law), 2015, vol. 6, no. 1. DOI: 10.17150/2072-0904.2015.6(1).18. (In Russian).

6. Omelchenko A.A. Innovative development of the Russian economy. Molodoy uchenyi= Young Scientist, 2011, vol. 1, no. 12, pp. 167-170. (In Russian).

7. Kozlova Zh. M. Analysis of approaches to classification of innovations. Vestnik Altaiskoi akademii ekonomiki i prava = Bulletin of Altai Academy of Economics and Law, 2011, no. 4, pp. 65-67. (In Russian).

8. Yakovts Yu. V. (ed.). Innovatsii: teoriya, mekhanizmy, gosudarstvennoe regulirovanie [Innovations: theory, mechanisms, governmental regulation]. Moscow, Russian Presidential Academy of National Economy and Public Administration Publ., 2002. 237 p.

9. Ogloblin V. A, Vikhorev V. G., Vikhoreva M. V. Some aspects of service approach to the concept «innovation». Izvestiya Irkutskoy gosudarstvennoy ekonomicheskoy akademii (Baykalskiy gosudarstvennyy universitet ekonomiki i prava) = Bulletin of Irkutsk State Economics Academy (Baikal State University of Economics and Law), 2015, vol. 6, no. 3. DOI: 10.17150/20720904.2015.6(3).22. (In Russian).

10. Kotler P., Bowen J. T., Makens J. C. Marketing for Hospitality and Tourism. $2^{\text {nd }}$ ed. New Jersey, Upper Saddle River, Prentice Hall, 1996. 800 p. (Russ. ed.: Kotler F., Bowen J., Makens J. Marketing. Gostepriimstvo. Turizm. Moscow, Unita-Dana Publ., 2002. 1063 p.).

11. Aksenov A. Mezhdunarodnye reitingi razvitiya IKT [International ICT Development Ratings. 2014]. Available at: http:// d-russia.ru/mezhdunarodnye-rejtingi-urovnya-razvitiya-ikt.html. (In Russian).

\section{Baikal Research Journal}


12. Kireyenko A. P., Sanina L. V. Application of program-targeted method for governmental support of small and medium-sized businesses in the regions of the Siberian Federal District. Izvestiya Irkutskoy gosudarstvennoy ekonomicheskoy akademii = Bulletin of Irkutsk State Economics Academy, 2014, no. 4 (96), pp. 117-132. (In Russian).

\section{Информация об авторах}

Оглоблин Владилир Александрович - старший преподаватель, кафедра менеджмента, Иркутский государственный университет путей сообщения, 664074, г. Иркутск, ул. Чернышевского, 15, e-mail: ogloblinva@mail.ru.

Вихорев Василий Григорьевич - кандидат технических наук, доцент, кафедра автоматизации производственных процессов, Иркутский государственный национальный исследовательский технический университет, 664074, г. Иркутск, ул. Лермонтова, 83, e-mail: vikhorev_vg@mail.ru.

Вихорева Мария Васильевна - кандидат экономических наук, доцент, кафедра экономики и государственного управления, Байкальский государственный университет, 664003, г. Иркутск, ул. Ленина, 11, e-mail: vmv2000@mail.ru.

\section{Authors}

Vladimir A. Ogloblin - Senior Lecturer, Chair of Management, Irkutsk State Railway Engineering University, 15 Chernyshesky St., 664074, Irkutsk, Russian Federation; e-mail: ogloblinva@mail.ru.

Vasiliy G. Vikhorev - PhD in Engineering, Associate Professor, Chair of Technological Processes Automation, Irkutsk National Research Technical University, 83 Lermontov St., 664074, Irkutsk, Russian Federation; e-mail: vikhorev_vg@mail.ru.

Maria V.Vikhoreva - PhD in Economics, Associate Professor, Chair of Economics and Public Administration, Baikal State University,11 Lenin St., 664003, Irkutsk, Russian Federation; e-mail: vmv2000@mail.ru.

\section{Библиографическое описание статьи}

Оглоблин В. А. Способы повышения степени инновационности экономики / В. А. Оглоблин, В. Г. Вихорев, М. В. Вихорева // Baikal Research Journal. — 2016. — T. 7, № 2. — DOI : 10.17150/2411-6262.2016.7(2).14.

\section{Reference to article}

Ogloblin V. A., Vikhorev V. G., Vikhoreva M. V. Ways of increasing the degree of economic innovativeness. Baikal Research Journal, 2016, vol. 7, no. 2. DOI: 10.17150/24116262.2016.7(2).14. (In Russian).

\section{Baikal Research Journal}

